\title{
Videoconference-based education for psychiatry registrars at the University of KwaZulu-Natal, South Africa
}

\author{
J Chipps', S Ramlall'2, M Mars' \\ 'Department of TeleHealth, University of KwaZulu-Natal, Durban, South Africa \\ 2Department of Psychiatry, University of KwaZulu-Natal, Durban, South Africa
}

\begin{abstract}
Objective: Psychiatry registrars form the backbone of specialized psychiatric service provision in South Africa. Medical schools are centralized while clinical services need to be widespread and accessible. Video-conferencing has the potential to link registrars at satellite hospitals with academic centers. The study thus evaluated of the use of videoconferencing in a Psychiatry Education Program delivered via videoconferencing. Method: To evaluate the implementation of the videoconference-based psychiatry registrar program, a pre- and post evaluative design was used. This involved all registrars in the 2008 and 2009 academic education program at the University of KwaZulu-Natal, South Africa. Access to education, satisfaction, suitability and costs of the psychiatry registrar education were studied. Results: In the evaluation of the Registrar Program, general satisfaction with the videoconferencing program was reported, though concerns were expressed about the level of interaction using this mode, the quality of the transmitted pictures of the anatomy specimens and the quality of the sound. Access to education was improved with potential cost savings identified. Conclusion: Well supported and planned videoconference-based teaching is a feasible, cost-effective and acceptable method of supporting registrars at sites distant from academic centers.
\end{abstract}

Keywords: Videoconferencing; Psychiatry; Education; South Africa

Received: 09-10-2011

Accepted: 14-05-2012

doi: http://dx.doi.org/10.4314/ajpsy.v15i4.32

\section{Introduction}

Low and Middle Income Countries have a high burden of psychiatric disorders, a shortage of psychiatrists ${ }^{1}$ and not enough psychiatry education centers. The situation is more urgent in Africa with only 47.4\% of African countries providing psychiatry education. ${ }^{2}$ South Africa has well established psychiatric education programs ${ }^{3}$ based at 8 medical schools across the country, but psychiatrists believe that education in psychiatry has lagged behind other major disciplines. ${ }^{4}$ In addition, postgraduate medical education in South Africa, as in most other African countries, faces considerable difficulties due to high service demands competing for 'academic' time, the constant drain of experienced staff to the private or overseas market, staff shortages and reduced time for supervision. ${ }^{5}$

\section{Correspondence}

Ms J Chipps

Nelson R Mandela School of Medicine, University of KwaZulu-Natal

Private Bag 7, Congella, 4013, South Africa

email: chipps@ukzn.ac.za

\section{Videoconference-based teaching}

The World Psychiatric Association has stated that it is essential for those involved in educating the next generation of psychiatrists to ensure that they are exposed to high quality knowledge and clinical settings using educational programs such as interactive computer based and telemedicine based educational programs. ${ }^{6}$

Telemedicine based educational programs or videoconferencing in psychiatry is not new with closed circuit television used for psychiatry education as early as 1956. ${ }^{7}$ Advances in technology now allow videoconferencing using fixed phone lines and more recently Internet Protocol (IP) for connectivity. Videoconference-based teaching is synchronous with live visual and verbal interaction between presenters and participants supported by teaching aids such as slide presentations, demonstration models and documents. ${ }^{8}$ It is a useful adjunct to traditional education and provides opportunities for participants in rural and remote areas who, due to time, travel, and cost constraints, would normally be unable to participate. ${ }^{9}$ 
Videoconference-based education is an integral component in many telehealth services in countries such as Australia ${ }^{10}$ and include activities such as journal clubs, ward rounds, continuing and formal medical education. ${ }^{11-26}$ Studies evaluating these activities have reported general satisfaction with the use of videoconferencing and no difference in educational outcomes compared to traditional face to face teaching. ${ }^{11-26}$

The Nelson R Mandela School of Medicine at the University of KwaZulu-Natal has increased the psychiatry registrar posts three-fold over the last three decades. Since 2008, 31 registrars have occupied full-time posts funded by the Department of Health at the eight accredited teaching hospitals for psychiatry dispersed throughout the province. These registrars contribute substantially to the psychiatric services in the public sector, while at the same time having to attend the twice weekly lecture/seminar academic program required by the University and the College of Psychiatry. The combination of local service demands, travelling distances of 100 to $300 \mathrm{~km}$ to the medical school and the costs associated with this, pose significant challenges to registrars at peripheral hospitals. To address these challenges, in 2008 the University's Department of Psychiatry with the assistance of the Department of TeleHealth commenced videoconference-based teaching to registrars in the Masters of Medicine Program for specialist registration in Psychiatry.

The Department of TeleHealth has been providing videoconference-based teaching at the Medical School since 2001 . Thirty-five postgraduate academic programs were delivered via videoconferencing in 2010 , with over 1,477 hours of interactive teaching broadcast to up to 8 sites simultaneously. ${ }^{27}$

The aims of this study were to: 1) review the literature on videoconference-based formal psychiatry education programs and 2) evaluate the use of videoconferencing for education in the psychiatry registrar academic program at the University.

\section{Method}

\section{Review of the Literature}

To review the relevant literature on the use of videoconferencing in psychiatric registrar of general medical psychiatry education, search terms ((psychiatry and (registrar or residen*) and (education or training) and (videoconference or videoconferencing)) were used to search the following databases: Academic Search Complete, PubMed, CINAHL, Health Source, PsychINFO and ERIC. The search was widened to identify relevant videoconference-based psychiatry education programs for registrars such as ongoing education for psychiatrists, but synchronous live streaming and asynchronous video teaching and general mental health training to general health students or staff were excluded.

\section{Evaluation of videoconference-based Education Program} In 2008, videoconferencing commenced for psychiatry registrar education consisting of two sessions per week from the Medical School to three and four distant sites respectively. The sessions consisted of Part 1: Neuroanatomy, Neurophysiology, Behavioral Sciences (5 hours/week) and Part 2: Psychiatry (General and Special) (1.5 hours/week). All of the videoconference connections were by Integrated Services Digital Network (ISDN) phone lines, at $128 \mathrm{kbps}$. The Medical School site, with a multipoint control unit, acted as the hub and the Department of TeleHealth provided the coordination and the technical support for the sessions.

To evaluate the implementation of the videoconferencebased psychiatry registrar education program, a single group initial and subsequent test evaluative design was used. The study received ethical clearance from the University Biomedical Research Ethics Committee.

The evaluation was conducted using the number of registrars for each session at each site from a routine attendance record log and a standard Department of TeleHealth videoconference participant evaluation form. The evaluation form was developed by the Department of TeleHealth and focuses on the implementation process and the participants' satisfaction with videoconferencing as an education tool against a set of quality criteria and indicators. The criteria are based on a review of the literature which identified four core areas for evaluation: Access to education, satisfaction, appropriateness of videoconferencing as an educational tool, and technical issues. ${ }^{28}$ Each criterion was measured using a number of questions using a 4-point Likert scale (Strongly Agree, Agree, Disagree, Strongly Disagree or Very Satisfied, Satisfied, Dissatisfied, Very Dissatisfied). Reliability was tested for the overall tool and for individual constructs using Chronbach's $\alpha$ for internal consistency. As the psychiatry registrar program runs over two years, the evaluation form was administered three times during the two years and all the registrars in the 2008 and 2009 programs were included

All data collected were entered and analyzed in SPSS version 18.0 (2010). The Likert scale was converted to a binary scale of Agree (1) and Disagree (0) or Satisfied (1) Dissatisfied (0). Descriptive statistics for a full data set were calculated with reported proportions of registrars agreeing and disagreeing against a standard of agreement or satisfaction (< 50\% poor; $50-74 \%$ moderate and => 75\% good agreement). Agreements between registrars from the central site and the distant sites were tested using Fischer's Exact Test, two-tailed. Paired evaluations completed by the same registrars, were compared using McNemars' Tests of Significance, two-tailed. ${ }^{29}$ Alpha was set as 5\% and only statistics where differences between the agreements were significant are reported. Potential cost savings were estimated by calculating potential travel cost reduction for individual registrars set off against the cost of establishing and running the videoconference units.

\section{Results}

\section{Review of the Literature}

No studies of videoconference-based education in psychiatry were found for Africa. Seven papers were found on the use of videoconferencing in psychiatry registrar education. These included a discussion of using videoconferencing as an assessment technology for preparations for psychiatric board examinations ${ }^{30}$, a discussion on using videoconferencing to provide continuity of psychiatry residency programs post the 


\begin{tabular}{|c|c|c|c|c|c|}
\hline & Year & Type Article & Education & Program & Outcomes \\
\hline Quinlan30 & 2009 & Letter & $\begin{array}{l}\text { Assessment: } \\
\text { Board Exam }\end{array}$ & $\begin{array}{l}\text { Mock examination via telepsychiatry } \\
\text { Six preparation evaluations to be completed } \\
\text { by the psychiatrist with the consultant } \\
\text { psychiatrist serving as the mock examiner }\end{array}$ & $\begin{array}{l}\text { Provides an opportunity to assess and } \\
\text { critique an examinee without the limitation of } \\
\text { travel and with minimal coordination of } \\
\text { appointments }\end{array}$ \\
\hline Griffies $^{31}$ & 2009 & Description & $\begin{array}{l}\text { Psychiatry } \\
\text { Education }\end{array}$ & $\begin{array}{l}\text { Post disaster establishment of Psychiatry } \\
\text { Residency Program }\end{array}$ & $\begin{array}{l}\text { Importance of using videoconferencing to } \\
\text { continue psychiatry education post disasters }\end{array}$ \\
\hline Greenwood ${ }^{24}$ & 2008 & Evaluation & $\begin{array}{l}\text { Continuing } \\
\text { Medical } \\
\text { Education for } \\
\text { Psychiatrists }\end{array}$ & $\begin{array}{l}5 \text { Rural and } 1 \text { metropolitan area }(n=106) \\
\text { (67\% consultant psychiatrists, } 17 \% \text { trainees } \\
\text { and } 16 \% \text { allied health professionals). }\end{array}$ & $\begin{array}{l}\text { Favorable views of the content and quality } \\
\text { of the presentations and impact on practice } \\
\text { patterns. } \\
\text { Opportunities to obtain credits. } \\
\text { Involvement enabled interaction among } \\
\text { peers throughout Australia, alleviating } \\
\text { professional isolation and generating } \\
\text { networking opportunities }\end{array}$ \\
\hline Ekblad $^{32}$ & 2004 & Pilot Evaluation & \begin{tabular}{|l|} 
Videoconference \\
with international \\
psychiatry teachers \\
from Australia, \\
Sweden and the USA
\end{tabular} & 10 senior Swedish medical students & $\begin{array}{l}\text { Favorable evaluation, } \\
\text { Importance of preparing students to } \\
\text { ensuring that the technology operates } \\
\text { smoothly to ensure success. }\end{array}$ \\
\hline Walter ${ }^{33}$ & 2004 & $\begin{array}{l}\text { Process } \\
\text { Evaluation }\end{array}$ & $\begin{array}{l}\text { Psychiatric Registrar } \\
\text { Education }\end{array}$ & $\begin{array}{l}\text { Seminar series utilizing interactive } \\
\text { videoconferencing and a web-based course } \\
\text { management system }\end{array}$ & $\begin{array}{l}\text { Trainees with access to high-speed real-time } \\
\text { connections rated their experience more } \\
\text { highly compared with those who used } \\
\text { slower web streaming technology, } \\
\text { particularly with regard to the sound quality }\end{array}$ \\
\hline Gammon ${ }^{34}$ & 1998 & $\begin{array}{l}\text { Qualitative } \\
\text { Evaluation }\end{array}$ & $\begin{array}{l}\text { Psychotherapy } \\
\text { supervision } \\
\text { Psychiatric } \\
\text { Registrars }\end{array}$ & $\begin{array}{l}6 \text { supervision pairs conducted } 5 \\
\text { videoconference-based supervision sessions } \\
\text { ( } 384 \text { kbs) and } 5 \text { in person sessions } \\
\text { alternating weekly for } 10 \text { sessions. }\end{array}$ & $\begin{array}{l}\text { Quality of supervision can be satisfactorily } \\
\text { maintained by using videoconferencing for } \\
\text { up to half of time }\end{array}$ \\
\hline
\end{tabular}

Katrina disaster in America ${ }^{31}$ and five evaluation studies of videoconference-based education for psychiatry registrar education programs (Table I). ${ }^{24,30-34}$ Overall, the evaluation studies reported satisfactory outcomes for using videoconferencing for teaching psychiatry, but the authors of the pilot evaluation commented that videoconferencing was seen to be still out of the reach of education programs in many developing countries where it was most needed. ${ }^{32}$

\section{Evaluation of videoconference-based Education Program}

The evaluation questionnaire was reliable and internally consistent (Chronbach's $\alpha$ 0.869) and was administered three times: in February 2008 ( $n=27), 6$ months into the program in August 2008 ( $\mathrm{n}=18$ ) and in May 2009 ( $\mathrm{n}=25)$. New registrars entered the program at different times during the evaluation period and the second and third ratings included registrars who were experiencing videoconferencing for the first time. Most registrars also attended both Part A and Part B. A total of 70 ratings were received from 41 registrars over the three assessments, with 18 registrars completing paired evaluations.

At the initial evaluation, two thirds (18/27) of the registrars rated themselves as familiar with videoconferencing. By the subsequent evaluations, all but one rated themselves as familiar with videoconferencing $(p=0.046)$.

\section{Criterion 1 - Access to Psychiatry Registrar Education}

Access to the videoconference-based Psychiatry Registrar Education Program was measured using hours of videoconference-based education broadcast, registrars' attendance and the reduction in travel resulting in potential time and cost savings.

\section{Hours of videoconference-based education broadcast} During 2008 and 2009, 6.5 hours of formal psychiatry teaching was broadcast in each week ( 5 hours for Part 1 and 1.5 hours for Part 2). Over the 18 weeks of teaching from February to June 2009, a total of 793 attendances and 117 hours of teaching were recorded. Attendance ranged from 10 to 15 registrars per session for Part 1 and from 28 to 34 registrars per session for Part 2.

\section{Registrars' Attendance}

From the first to the third evaluations, the percent of registrars who reported attending from a distant site (and subsequently did not drive to the Medical School) increased from $7 / 27$ (25.9\%) to $7 / 18$ (38.8\%) to 19/25 (76\%), (Chi-square 13.7, p=0.001), implying increasing familiarity and acceptance of videoconferencing in the registrar cohort. 


\section{Reduction in travel}

The use of videoconference venues at the distant sites resulted in a substantial reduction in travel for the registrars. Nineteen of the 33 (59.9\%) distant participant evaluations specifically listed travel reduction as an advantage and reported saving on average $183 \mathrm{~km} \pm 108$ [95\% CI $144-221$ ] in return journeys to and from the medical school for each session.

\section{Potential Cost and Time Savings}

In the first six month period, registrars from distant sites would have travelled an estimated $94,950 \mathrm{~km}$ to and from the medical school. If the university travel allowance of R2.92 or $\$ 0.40 / \mathrm{km}$ is used, the total travel cost of attending the education sessions would have been R276,203 for the period or R15,345 per week. The actual costs of running the service during that period was estimated as R64,678 or R3,593 per week (standard call tariffs for two ISDN lines @ R0.01083ps ${ }^{35}$ and rentals of R229.32 per line per month for the sites and not discounting phone line use by other programs). The cost for setting up two new venues for psychiatry in the psychiatric hospitals was estimated at R240,000, but the cost should be divided between all services using the infrastructure. Excluding the Medical School sites, the potential cost saving using videoconferencing would have paid for the set up of the two local videoconference venues within six months.

\section{Criterion 2 - Overall appropriateness of videoconferencing as a teaching tool in Psychiatry} Overall appropriateness of videoconferencing (Chronbach's $\alpha$ 0.71) as a teaching tool was measured using questions comparing videoconference-based teaching to traditional face to face teaching in terms of effectiveness, interaction and appropriateness for teaching psychiatry (Table III). Comparisons of before and after ratings were done on the 18 paired evaluation using McNemar's Test.
Videoconferencing was perceived as an excellent education tool (Table II), even though there was a small, non significant drop in the paired post evaluations [15/18 (83.3\%)] to [12/18 (66.7\%) p=.357]. It was also perceived to be an appropriate tool to teach psychiatry by more than half the registrars and this remained unchanged in paired post evaluations [10/18 (55.6\%)] (Table III). There was a preference for face to face teaching with only seven of the 18 registrars (38.9\%) indicating that videoconferencing was as effective as face to face teaching. This was sustained in paired post evaluations [7/18 (38.9\%)] Contributing to these figures were the low ratings for interaction with only $27.8 \%(5 / 18)$ pre and $22.2 \%(4 / 18)$ post evaluation indicating that videoconferencing allowed for the same level of interaction. These figures were not affected by whether the registrar was in a venue with face to face interaction with the lecturer, indicating that factors other than technology are at play.

\section{Criterion 3 - Overall satisfaction with videoconference as a teaching tool}

Overall satisfaction with videoconferencing as a teaching tool (Chronbach's $\alpha$.71) was measured using questions rating participant's satisfaction with videoconferencing as a teaching tool, overall satisfaction with presenters using videoconferencing, whether registrars would attend future sessions offered using videoconferencing and whether they would rather attend by videoconference than travel to Durban (Table III)

Registrars reported moderate satisfaction with the use of videoconference-based teaching program with the pre and post ratings of the four items' agreement levels were all above 50\% except for one post evaluation (Table III). Even though overall satisfaction with the videoconference presentations increased [12/18 (61.1\%) to $17 / 18(94.8 \%)$ $\mathrm{p}=.125]$, six registrars (three from medical school) changed agreements that they would prefer to attend more videoconference sessions in the future [15/18

Table II: Appropriateness of videoconference-based teaching in Psychiatry $(n=18)$

\begin{tabular}{|l|l|l|}
\hline Criteria & Evaluation & Evaluation 2 \\
\hline Videoconference-based teaching is as effective as traditional face to face teaching & $7(38.9 \%)$ & $7(38.9 \%)$ \\
Videoconference-based teaching allows for same level of interaction effective as traditional face to face teaching & $5(27.8 \%$ & $4(22.2 \%)$ \\
Videoconferencing is an excellent educational tool & $15(83.3 \%)^{*}$ & $12(66.7 \%)$ \\
Videoconferencing is an appropriate tool to teach psychiatry & $10(55.6 \%)$ & $10(55.6 \%)$ \\
\hline${ }^{*}=>75 \%$ & &
\end{tabular}

Table III: Satisfaction with videoconference-based education programs $(n=18)$

\begin{tabular}{|l|l|l|}
\hline Table III: Satisfaction with videoconference-based education programs (n=18) & Evaluation 1 & Evaluation 2 \\
\hline Criteria & $10(55.6 \%)$ & $10(55.6 \%)$ \\
$17(94.4 \%)^{*}$ \\
\hline Use of videoconferencing as an education tool & $12(66.7 \%)$ & $15(83.3 \%)^{*}$ \\
Overall presentation of program using videoconferencing & $11(55.6 \%)$ \\
Participant would attend more sessions offered by videoconferencing & $7(38.9 \%)$ \\
Participant would attend sessions by videoconferencing rather than travel to Medical School & \\
\hline${ }^{*}=>75 \%$ & & \\
\hline
\end{tabular}


(83.3\%) to 10/18 (55.6\%, $\mathrm{p}=.125)$, and four registrars (three from medical school) changed agreements that they would attend videoconferencing rather than travel [(1 1/18 $(61.1 \%)$ to $7 / 18(38.9 \%) \mathrm{p}=.219)$ ]. The ratings were also compared between registrars at the Medical School and registrars at the distant sites using Chi-square test for each of the evaluations but no significant differences were found for any of the evaluations or items.

\section{Criterion 4 - Technical issues}

Technical issues (Chronbach's $\alpha$.76) were measured using participants' satisfaction with audio quality during presentations and discussions, picture quality of presentations, discussions, using PowerPoint slides and models used for demonstration of neuro-anatomy (Table IV). Apart from satisfaction with the quality of PowerPoint slides, all ratings were below the standard of $75 \%$ and two ratings for audio quality were below 50\%.

\section{Audio quality}

There was significant agreement on dissatisfaction with audio quality for pre [8/8 (100\%) and 8/10 (80\%), p=.001] and post evaluation [6/9 (66.7\%) and 6/8 (75\%), $p=.053)$ during presentations and discussions respectively. This were mainly related to the dissatisfaction of the distant sites with discussions $(p=.03)$ as compared to presentation sound $(\mathrm{p}=.03)$.

\section{Picture quality}

There was significant agreement on levels of satisfaction with picture quality of pre [1 1/1 (100\%) and $11 / 13$ (84.6\%), $\mathrm{p}=.002]$ and post evaluations [10/10 (100\%) and 10/11 (90.9\%), $\mathrm{p}=.002]$ during presentations and discussions respectively. Overall most registrars were satisfied with the picture quality during presentations and discussion, although satisfaction with picture quality during presentations reduced from [13/18 (72.6\%) to 10/18 (55.6\%), $\mathrm{p}=.727$ ].

\section{Use of teaching aids}

Overall, registrars were very satisfied with the quality of PowerPoint slides and no significant differences were found in pre (13/18) and post paired evaluations (16/18) $(\mathrm{p}=.375)$ (Table IV). There were no significant differences between registrars at the Medical School and the distant videoconference sites. Registrars were less satisfied with the use of anatomy specimens during videoconference- based teaching. Only 10/18 (55.6\%) of registrars pre evaluation and $11 / 18$ (61.1\%) post evaluation were satisfied with seeing the specimens $(p=.954)$ (Table IV). There were no significant differences between registrars at the Medical School and the distant videoconference sites. The specific problems identified were the poor quality of pictures of the models at 128kbps and not being able to identify color in the drawings.

\section{Discussion}

There are few papers on videoconference-based education for psychiatric registrar education and no papers of psychiatric videoconference-based education in Africa were found. The papers reviewed found satisfactory outcomes for using videoconferencing for teaching psychiatry, but it was noted that videoconferencing was seen to be still out of the reach of the education programs in many developing countries where it was most needed. This makes the implementation and evaluation of this program important for providing useful information for psychiatry education in the country.

Videoconference-based psychiatric registrar education has been successfully implemented with twice weekly interactive sessions being broadcast to three and four distant sites respectively and registrars attending these sessions from their local hospitals. The registrars now have a high familiarity with videoconference education and the use of videoconferencing for psychiatry registrar education has facilitated the participation of registrars based at peripheral teaching hospitals in the psychiatric registrar program, with major potential cost and time savings. The establishment of a videoconferencebased program for psychiatric registrars has also resulted in the development of two telepsychiatry venues in psychiatric hospitals, opening up the possibility of expanding to clinical services.

Overall, the registrars expressed satisfaction with the use of videoconferencing. This finding is similar to reported studies on the use of videoconferencing in psychiatry education which reported favorable evaluation of content and quality of videoconference based education for psychiatry. ${ }^{23,24,36-38}$ There were small nonsignificant drops in satisfaction with videoconferencing in the subsequent paired evaluations. These can be ascribed to the normal adjustment to videoconference teaching, the lack of technical support at the distant sites, and inexperience of presenters (both staff and registrars) in

\section{Table IV: Satisfaction with Technical criteria $(n=18)$}

\begin{tabular}{|c|c|c|}
\hline Criteria & Evaluation 1 & Evaluation 2 \\
\hline Audio quality during presentations & $10(55.6 \%)$ & $9(50 \%)$ \\
\hline Audio quality during discussions & $8(44.4 \%)$ & 7 (38.9\%) \\
\hline Picture quality during presentations & $13(72.2 \%)$ & $10(55.6 \%)$ \\
\hline Picture quality during discussions & $11(61.1 \%)$ & $11(61.1 \%)$ \\
\hline Picture quality of PowerPoint slides & $13(72.2 \%)$ & $16(88.9 \%)^{\star}$ \\
\hline Picture quality of anatomy specimens or models & $10(55.6 \%)$ & $11(61.1 \%)$ \\
\hline
\end{tabular}


facilitating discussion at multiple sites. Using specimens for anatomy teaching was not effective at either the local or distant sites. Registrars were satisfied with the quality of the video pictures and PowerPoint presentations, but were not satisfied with the quality of the sound. This finding differs from other evaluations conducted on newly commenced programs at the Medical School where the acceptability of slides developed for normal face to face presentations were not always suitable for videoconference presentations. ${ }^{39}$ This difference could be attributed to the explicit instructions and training provided on slide requirements for optimal videoconference-based teaching and the use of the slides when the sound quality were poor.

There was a general perception that videoconferencing was not as effective as face to face teaching with the main reason given the reported lower level of interaction using videoconference. This may relate to the teaching methods used in the program, the format of the Part II presentations where registrars resorted to formal presentations, presenter experience in videoconference and the suitability of teaching neuro-anatomy via videoconference. Problems relating to audio quality were addressed and improvement was reflected in subsequent evaluations. Reviews on child and adolescent psychiatry studies ${ }^{40}$ and adult studies ${ }^{41}$ also mentioned the audiovisual quality of the videoconference as one of the drawbacks.

Issues for success in future should include the importance of preparing participants and staff on the educational and technological requirements of videoconference-based teaching. It is important to ensure that the technology operates smoothly and to improve the speed of connections. 32,33 The cost of implementing videoconferencing can by significantly reduced using desktop videoconferencing software, a data projector, running on university or Department of Health LANs. Further research is also required on the use of modern education theory when teaching by videoconference. ${ }^{42}$

Overall, the evaluation tool appears to be reliable with adequate Chronbach's $\alpha$ values for the overall tool and the separate constructs; however, the study was limited by the low level of paired evaluations. There is also a need to conduct more research on the effectiveness of videoconference education including comparing actual knowledge and skill outcomes between different sites. This was not done due to the inability to compare examination results between Medical School and distant sites as there was a high changeover and movement of registrars and only a few registrars sat examinations during the period.

This study did not address using videoconference for assessment but new papers have emerged on the use of videoconferencing for the preparation for board certification which would provide an opportunity to assess and critique an examinee without the limitation of travel. ${ }^{30}$ The use of videoconferencing for psychiatry education may in future impact on practice patterns, future opportunities to obtain Continuing Professional Development credits and the alleviation of professional isolation. ${ }^{24,30}$ There is also potential to expand the educational use of videoconferencing to clinical supervision, mentoring and oral board examination preparation and examination, not only in South Africa but in Africa.

\section{Conclusion}

The time saved in not having to travel to the Medical School is substantial and denotes time gained for clinical duties or own study and makes videoconferencing a cost effective method for registrar education. Using videoconferencing for psychiatry education can also provide education and support opportunities for psychiatrists and trainees in Africa by linking universities with academic psychiatry programs to countries and medical schools without such programs.

Running a successful videoconference education program requires skill to initiate, implement and evaluate as well as to maintain effective technology. It requires a paradigm shift in teaching that needs to embrace modern technology and acceptance of distributed learning and the fact that educators and students need not be confined to academic centers. ${ }^{43,44}$ The University of KwaZulu-Natal has substantial experience in delivering videoconference education and has the potential to meet the academic needs of rural-based and African learners with minimum impact on service delivery and substantial time and cost savings.

\section{References}

1. World Health Organisation. Mental Health Atlas 2005. Geneva: WHO., 2005.

2. Saxena S. Atlas : psychiatric education and training across the world: World Health Organization.; 2005.

3. Emsley R. Focus on psychiatry in South Africa. Br J Psychiatry 2001;178(4):382-386.

4. Stein DJ, Betancourt OA, Emsley RA, Jeenah Y, Mkize D, Pretorius J, et al. Sub-specialties in psychiatry: towards parity in mental health training and services. S Afr Med J 2009;99(1):38-39.

5. Naidu T, Ramlall S. Establishing psychiatric registrars' competence in psychotherapy: a portfolio based model. Afr J Psychiatry 2008;11(4):264-271.

6. Tasman A. Update on WPA Education Programs, 2009. World Psychiatry 2009;8(3):190-191.

7. Wittson CL, Dutton R. Interstate telecommunication. Ment Hos 1957;2:15-17.

8. Curran VR. Tele-education. J Telemed Telecare 2006;12(2):57-63.

9. Ahn HH, Kim JE, Ko NY, Seo SH, Kim SN, Kye YC. Videoconferencing journal club for dermatology residency training: an attitude study. Acta Derm Venereol 2007;87(5):397-400.

10. Dillon E, Loermans J, Davis D, Xu C. Evaluation of the Western Australian Department of Health telehealth project.J Telemed Telecare 2005;11 (Suppl 2):19-21.

11. Klein D, Davis P, Hickey L. Videoconferences for rural physicians' continuing health education. J Telemed Telecare 2005;11 (Suppl 1):97-99.

12. Allen M, Sargeant J, MacDougall E. Videoconferenced continuing medical education in Nova Scotia. J Telemed Telecare 2002;8 (Suppl 3):2-4.

13. Allen M, Sargeant J, MacDougall E, O'Brien B. Evaluation of videoconferenced grand rounds. J Telemed Telecare 2002;8(4): 210-216.

14. Fitzgerald A, Bailey $M$, Smith AC, Webb K, Keating D, Klepper K, et al. Child development services: a multidisciplinary approach to professional education via videoconference. J Telemed Telecare 2002;8 (Suppl 3):19-21.

15. Allen $M$, Sargeant J, Mann $K$, Fleming $M$, Premi J. Videoconferencing for practice-based small-group continuing medical education: feasibility, acceptability, effectiveness, and cost. 
J Contin Educ Health Prof 2003;23(1):38-47

16. Callas PW, Bertsch TF, Caputo MP, Flynn BS, Doheny-Farina S, Ricci $M A$. Medical student evaluations of lectures attended in person or from rural sites via interactive videoconferencing. Teach Learn Med 2004;16(1):46-50.

17. Ho D, Hu P, Carmack D, Hayda R, Pohl A, Dunbar R, et al. Design and evaluation of International Video Teleconference (iVTC) for orthopedic trauma education. AMIA Annu Symp Proc 2006:951.

18. Karlinsky H, Dunn C, Clifford B, Atkins J, Pachev G, Cunningham K, et al. Workplace injury management: using new technology to deliver and evaluate physician continuing medical education. J Occup Rehabil 2006;16(4):719-730.

19. Kidd RS, Stamatakis MK. Comparison of students' performance in and satisfaction with a clinical pharmacokinetics course delivered live and by interactive videoconferencing. Am J Pharm Educ 2006;70(1):10

20. Allen M, Mann K, Kells C, Ferrier S, O'Connor N, MacDonald P. Cardiology grand rounds: effect of videoconferencing on educational value. J Telemed Telecare 2007;13(3):136-141.

21. Goodale BJ, Spitz S, Beattie NJ, Lin IB. Training rural and remote therapy assistants in Western Australia. Rural Remote Health 2007;7(3):774

22. Moridani M. Asynchronous video streaming vs. synchronous videoconferencing for teaching a pharmacogenetic pharmacotherapy course. Am J Pharm Educ 2007;71 (1):16.

23. Xavier K, Shepherd L, Goldstein D. Clinical supervision and education via videoconference: a feasibility project. J Telemed Telecare 2007;13(4):206-209.

24. Greenwood J, Williams R. Continuing professional development for Australian rural psychiatrists by videoconference. Australas Psychiatry 2008;16(4):273-276.

25. Holland AJ, Soundappan SV, Oldmeadow W. Videoconferencing surgical tutorials: bridging the gap. ANZ J Surg 2008;78(4):297-301.

26. Newman C, Martin E, MCGarry DE, Cashin A. Survey of a videoconference community of professional development for rural and urban nurses. Rural Remote Health 2009;9(2):1134.

27. Mars M. Building the Capacity to Build Capacity in eHealth in subSaharan Africa: the KwaZulu-Natal Experience. Telemed J E Health 2012;18(1):32-37.

28. Chipps J. The Use of Synchronous Videoconferencing Teaching to Increase Access to Specialist Nurse Education in Rural KwaZuluNatal, South Africa. KM\&EL 2010;2(2):154-168.

29. Bland JM. An Introduction to Medical Statistics. Third ed. Oxford: Oxford Medical Press; 2003.

30. Quinlan PE, Farooqi SA, Magen JG. Telepsychiatry services and oral board examination preparation. Acad Psychiatry 2009;33(1):81-82.

31. Griffies WS. Post-Katrina stabilization of the LSU/Ochsner Psychiatry Residency Program: caveats for disaster preparedness. Acad Psychiatry 2009;33(5):418-422.
32. Ekblad S, Manicavasagar V, Silove D, Baarnhielm S, Reczycki M, Mollica $R$, et al. The use of international videoconferencing as a strategy for teaching medical students about transcultural psychiatry. Transcult Psychiatry 2004;41 (1):120-129.

33. Walter $D A$, Rosenquist $P B$, Bawtinhimer G. Distance learning technologies in the training of psychiatry residents: a critical assessment. Acad Psychiatry 2004;28(1):60-65.

34. Gammon D, Sorlie T, Bergvik S, Hoifodt TS. Psychotherapy supervision conducted by videoconferencing: a qualitative study of users' experiences. J Telemed Telecare 1998;4 (Suppl 1):33-35.

35. Telkom. Telkom call tariffs. 2010 [cited 2010 February]; Available from: http://www.telkom.co.za/general/pricelist/automatic exchanges_worldcall.html.

36. McLaren PM, Ball CJ, Summerfield AB, Lipsedge M, Watson JP. Preliminary evaluation of a low cost videoconferencing system for teaching in clinical psychiatry. Med Teach 1992;14(1):43-47.

37. D'Souza R. A pilot study of an educational service for rural mental health practitioners in South Australia using telemedicine.J Telemed Telecare 2000;6 (Suppl 1):187-189.

38. Hilty DM, Yellowlees PM, Nesbitt TS. Evolution of telepsychiatry to rural sites: changes over time in types of referral and in primary care providers' knowledge, skills and satisfaction. Gen Hosp Psychiatry 2006;28(5):367-373.

39. Chipps J, Mars M. Technology Enhanced Learning for Remote Nurses in KwaZulu-Natal. IST-Africa; Durban, Souoth Africa: ISTAfrica 2010 Conference Proceedings, Paul Cunningham and Miriam Cunningham (Eds), IIMC International Information Management Corporation, 2010, ISBN: 978-1-905824-15-1; 2010.

40. Pesämaa L, Ebeling H, Kuusimäki M-L, Winblad I, Isohanni M, Moilanen I. Videoconferencing in child and adolescent telepsychiatry: a systematic review of the literature. J Telemed Telecare 2004;10(4):187-192.

41. Hoolahan B, Grosvenor J, Kurtz H, Kelly B. Utilizing technology to raise mental health literacy in small rural towns. Learning in Health \& Social Care 2007;6(3):145-155.

42. Sweeney MA. The use of videoconferencing techniques which support constructivism in K-12 education. Dissertation Abstracts International Section A: Humanities and Social Sciences [serial on the Internet]. 2007 [cited 20121 May]; 68: Available from: http://vcoutonalim.org/ 2007/12/27/lit-review-the-use-of-video-conferencing-techniqueswhich-support-constructivism-in-k-12-education/.

43. Harvey RM, Horvath KJ, Levine SA, Volicer L. Models of Physician Education for Alzheimer' s Disease and Dementia: Practical Application in an Integrated Network. Clinical Gerontologist 2006;29(2):11-23.

44. Hilty DM, Alverson DC, Alpert JE, Tong L, Sagduyu K, Boland RJ, et al. Virtual reality, telemedicine, web and data processing innovations in medical and psychiatric education and clinical care. Acad Psychiatry 2006;30(6):528-533.

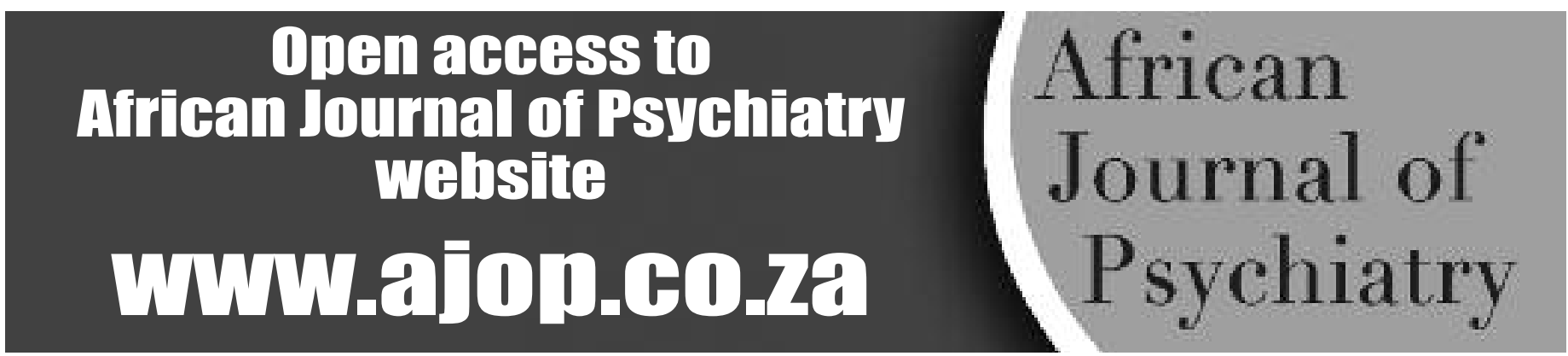

